\title{
Recurrence of Lower Eyelid Fat Pads (Herniated Fat) after Blepharoplasty: An Analysis of Different Operative Techniques
}

\author{
Riham Al Ashkar, Sinan Alboudi*, Anwar Alhassanieh \\ Department of Plastic Surgery, Faculty of Medicine, Damascus University, Damascus, Syrian Arab Republic \\ Email: `sinan986@yahoo.com,dranwar_h@yahoo.com,riham.alashkar@gmail.com
}

How to cite this paper: Al Ashkar, R., Alboudi, S. and Alhassanieh, A. (2021) Recurrence of Lower Eyelid Fat Pads (Herniated Fat) after Blepharoplasty: An Analysis of Different Operative Techniques. Modern Plastic Surgery, 11, 63-69.

https://doi.org/10.4236/mps.2021.113008

Received: June 9, 2021

Accepted: July 6, 2021

Published: July 9, 2021

Copyright (c) 2021 by author(s) and Scientific Research Publishing Inc. This work is licensed under the Creative Commons Attribution International License (CC BY 4.0).

http://creativecommons.org/licenses/by/4.0/

\begin{abstract}
Background: Aging changes to the lower eyelids and midface include all but not only these changes: pseudoherniated orbital fat, tear trough deformity, lid laxity, and dermatochalasis. Surgical repair often aims at treating redundant skin or orbital fat malposition with a lower eyelid blepharoplasty. In manipulating the inferior orbital fat pads, a surgeon has many options including excision, repositioning, or augmentation with synthetic dermal filler, autologous fat grafts, or acellular dermal allografts [1]. The aim of this study is to find the best approach in preventing fat herniation reccurnce in lower lid blepharoplasty. Methods: The patients in study were classified into three groups depending on the used surgical technique, to test the most effective technique associated with minimal rate of lower fat pad recurrence after surgery. Two of these techniques include a muscular flap suspension from the orbicularis oculae muscle. Results: The two surgical techniques that include orbicularis oculi muscle suspension are associated with no recurrence of lower herniated fat pads after blepharoplasty. Conclusions: The suspension of orbicularis oculi muscle has an important role in enhancing the lower orbital septum and prevents the recurrence of the lower herniated fat pads.
\end{abstract}

\section{Keywords}

Infraorbital Fat, Lower Lid Blepharoplasty, Lower Fat Pads, Orbicularis Oculi Muscle Suspension

\section{Introduction}

Lower lid bulge is known as a part of the aging process. Lower lid bulge can be produced by one of 2 major mechanisms or a combination of them: herniated 
excessive intraorbital fat and/or weakening of supporting components of the lower eyelid, including skin, orbicularis oculi muscle, orbital septum, capsulopalpebral fascia, Lockwood ligament, and lateral canthus [2] [3] [4] [5]. Lee et al. [6] reported that total orbital fat (OF) volume and fat volume of anterior to the inferior orbital rim (IORF) increased significantly after $40 \mathrm{~s}$ in both male and female groups compared with that of the $20 \mathrm{~s}$. The ratio of IORF to OF showed significant differences after $60 \mathrm{~s}$ compared with that of $20 \mathrm{~s}$.

Therefore treating these anatomic changes and avoiding their recurrence is an important part of periorbital rejuvenation surgery.

Many techniques have been described to treat this fat compartment bulging, with different results and different recurrence average was reported in medical records.

We used 3 different techniques here concentrating on recurrences after fat pads removal.

\section{Materials and Methods}

110 patients are undergoing aesthetic upper and lower blepharoplasty in our Plastic and Reconstructive division in Almowasat Hospital in Damascus from 2018 to 2021.

46 patients who were well followed up were retrospectively reviewed and categorized into three groups according to the surgical techniques employed.

All patients have undergone upper and lower blepharoplasty surgery, without any other associated procedures like face lifting, brow lifting, midface lift, or fat injection in face.

All patients with previous periocular surgery were excluded from the study, also we did exclude patients with periocular diseases (such as blepharoptosis, dry eye syndrome, ...)

It happened to be that all patients were females in the study but that was no inclusion chriteria.

\subsection{Group 1 (15 Patients)}

Upper and lower blepharoplasty with dissection of central and lateral part of lower eyelid orbicularis oculi muscle as flap ( $2 \mathrm{~cm}$ length, $0.5 \mathrm{~cm}$ width) from lower eyelid skin flap and suspension it on lateral orbital margin periosteum 2 $\mathrm{mm}$ above the level of the medial canthus via passing this muscle flap through a tunnel that was dissected beneath the skin flap lateral the lateral canthus and between the upper and lower blepharoplasty incisions (Figure 1).

This fixation of muscle flap was performed using 5/0 Nylon suture one mattress stitch $(\mathrm{n}=15)$.

\subsection{Group 2 (15 Patients)}

Upper and lower blepharoplasty were done with lateral lower eyelid tarsal plate suspension on lateral orbital margin periosteum $2 \mathrm{~mm}$ above medial canthus 
level without creating previous lateral tunnel (Figure 2).

This fixation of lateral lower eyelid tarsal plate was also performed with $5 / 0$ Nylon suture one mattress stitch $(n=15)$.

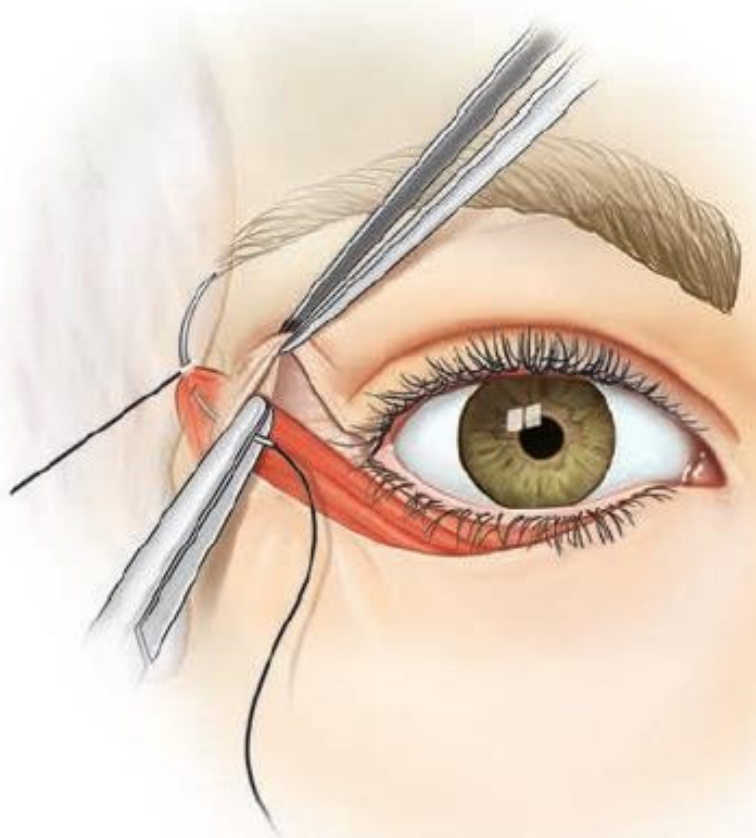

Figure 1. Group 1 orbicularis occulae flap suspension.

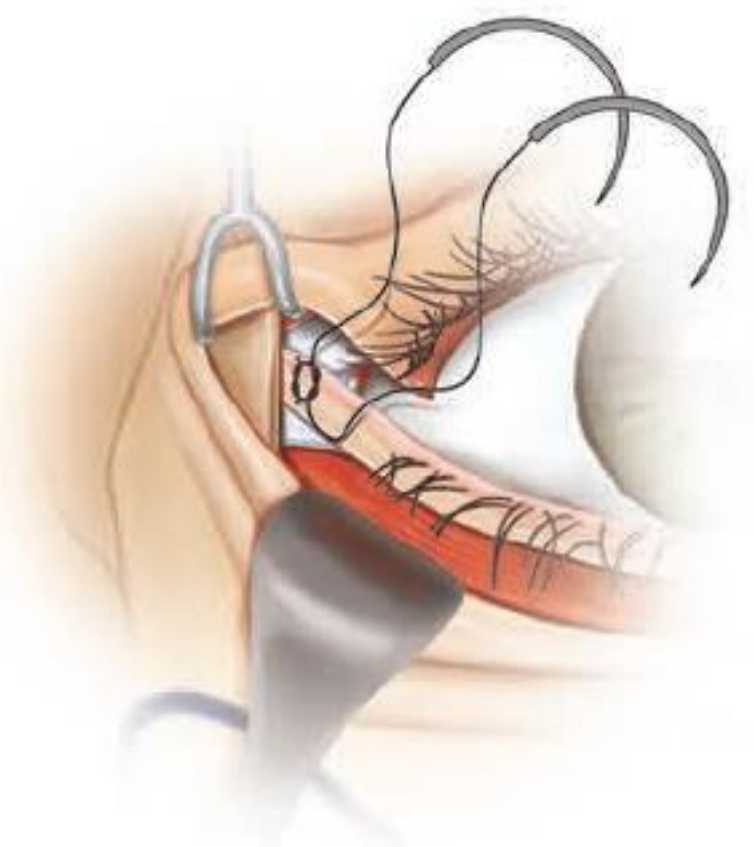

Figure 2. Group 2 tarsal plate suspension. 


\subsection{Group 3 (16 Patients)}

Upper and lower blepharoplasty with suspension of both lower eyelid orbicularis oculi muscle dissected flap and lateral lower eyelid tarsal plate on the lateral orbital margin periosteum $2 \mathrm{~mm}$ above medial canthus level via passing these structures through the tunnel that was dissected beneath the skin flap lateral the lateral canthus and between the upper and lower blepharoplasty incisions.

This fixation of these two anatomic structures was performed with one Nylon Matress stitch for each of them $(n=16)$.

The mean age was between $40-70$ years at surgery; the mean follow-up period was 1 year.

Clinical examination and Photographs were used to follow-up the patients.

The herniated fat pads were treated in all patients with using partial surgical excision or bipolar cauterizing, without using the repositioning technique, and without resuturing of lower incised septum (Table 1).

\section{Results}

The recurrence of lower eyelid pads occur in 4 patients in group 2, 4/15 (26.66\%) patients:

- 1 patient unilateral.

- 3 patients bilateral.

There is no recurrence in the whole patient groups $1+3$.

The recurrent fat pads in two patients were big, apparent, and have the same size before surgery.

In the other two patients the recurrent fat pads were moderate in size and appearance (Figure 3, Figure 4).

After more than 1 year of follow up no patients in groups 1 or 3 have any complaints about fat pad bulging relapse.

And the recurrence was determined by both the patient and the surgeon and according to previous pictures of the patient.

Recurrence patients requested another operation for fat pads more than 1 year sfter the first operation.

Table 1. Patients groups characteristics, $\mathrm{OO}=$ orbicularis oculae.

\begin{tabular}{cccc}
\hline Group number & $\mathbf{1}$ & $\mathbf{2}$ & $\mathbf{3}$ \\
\hline Number of Patients & 15 & 15 & 16 \\
Mean age (year) & 51 & 50.9 & 100 \\
Female percentage (\%) & 100 & 100 & Oo flap + tarsal suspension \\
Technique & OO flap & Tarsal suspension & 20.5 \\
Mean follow up (month) & 19.5 & 18 & 0 \\
Fat bad recurrence (\%) & 0 & 26.6 & \\
\hline
\end{tabular}




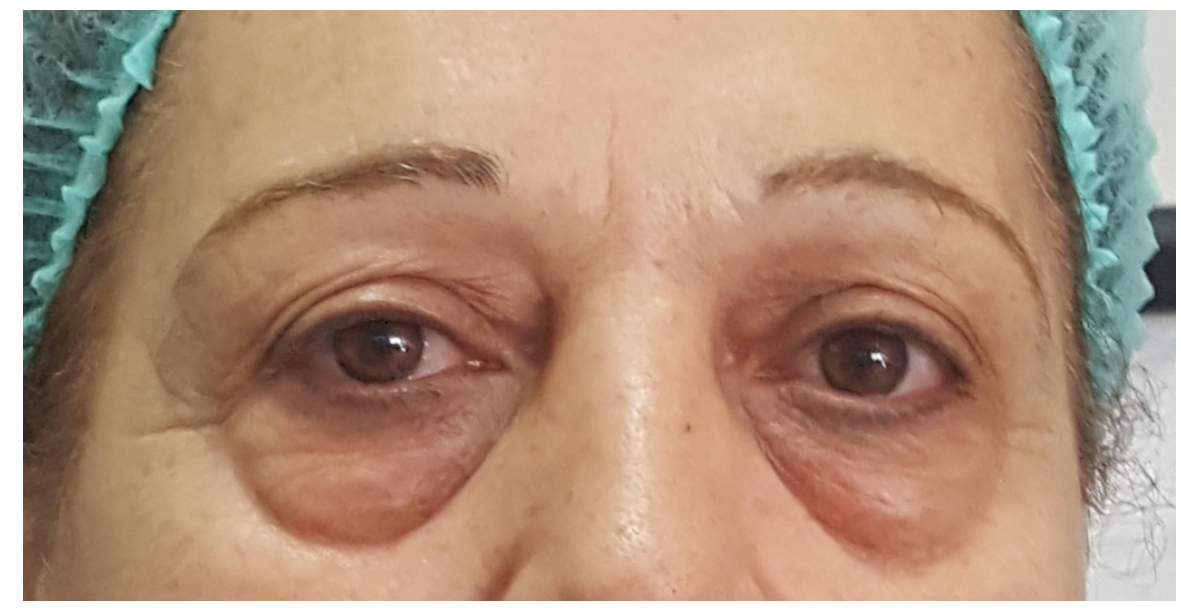

Figure 3. Patient before upper and lower blepharoplasty.

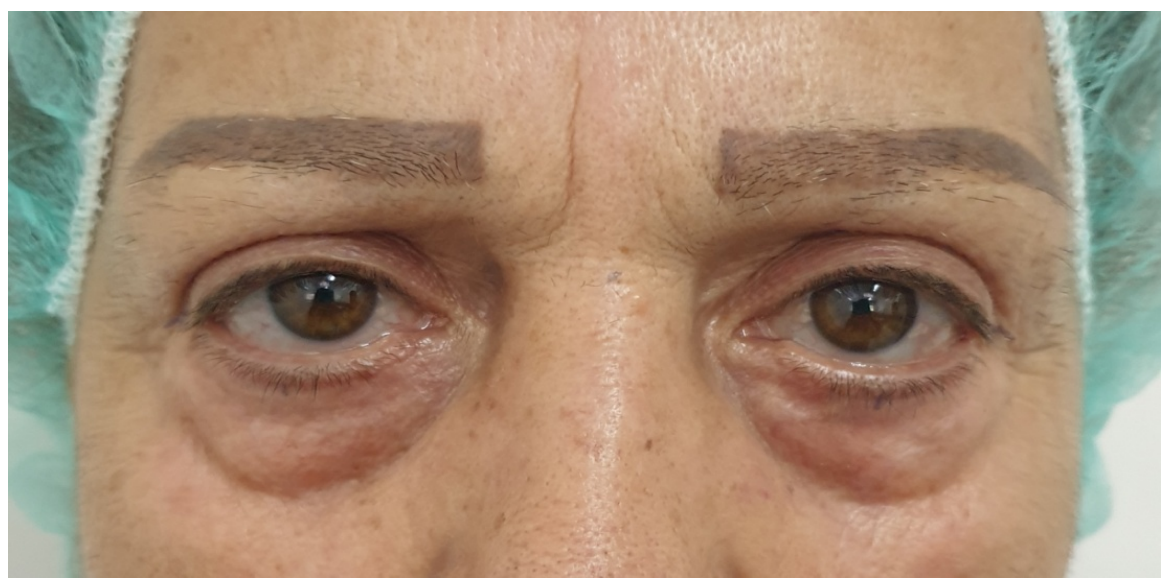

Figure 4. Patient after 1 year of upper and lower blepharoplasty with recurrent lower eyelid fat herniation.

\section{Discussion}

Different problems can be encountered when planning a lower blepharoplasty, such as festoons, prominent fat bags, and a conspicuous transition from eyelid to cheek. Frequently, they occur simultaneously. In such cases, a larger amount of skin excision is needed to achieve an adequate correction. This carries an increased risk of eyelid retraction when dealing with hypotonic eyelids. Orbicularis muscle suspension can provide vertical support to the eyelid and so achieve a safer, more effective correction.

Several techniques have been reported to obtain this effect. We have found a laterally based transposition orbicularis flap to be a safe and effective method to transmit a controlled amount of traction to the lower lid [7].

In our study we have found that suspension of the orbicularis oculi muscle has also an important role in supporting the lower orbital septum and prevent the recurrence of the lower herniated fat pads.

And our results are familiar to another international study which includes the following. 
While the incision of the orbicularis oculi muscle with lateral suspension of this muscle has been used by many authors to improve the tension of the lower eyelid [8]-[15]. They considered that the suspension of the orbicularis oculi muscle on the lateral orbital margin (with or without a true lateral canthus suspension) not only suspend the lower eyelid, but also improve the contour of the lower eyelid by redraping the skin and muscle, and by strengthening the orbital septum and consequently enhancing posterior placement of the herniated fat [16] [17] [18].

\section{Conclusions}

Suspension of the orbicularis oculi muscle in patients group $1+3$ has a significant role in preventing recurrence of the herniated fat pads after upper and lower blepharoplasty.

This study suggests that the anchorage of the orbicularis muscle flap to the upper lateral orbital rim prevents the recurrence of the lower fat pads after blepharoplasty, independent of lateral canthopexy or plasty.

\section{Conflicts of Interest}

The authors declare no conflicts of interest regarding the publication of this paper.

\section{References}

[1] Murri, A., Hamill, E.B., Hauck, M.J. and Marx, D.P. (2017) An Update on Lower Lid Blepharoplasty. Seminars in Plastic Surgery, 31, 46-50. https://doi.org/10.1055/s-0037-1598632

[2] Castanares, S. (1946) Blepharoplasty for Herniated Intraorbital Fat: Anatomical Basis for a New Approach. Plastic and Reconstructive Surgery, 8, 46-58. https://doi.org/10.1097/00006534-195107000-00003

[3] Camirand, A., Doucet, J. and Harris, J. (1997) Anatomy, Pathophysiology, and Prevention of Senile Enophthalmia and Associated Herniated Lower Eyelid Fat Pads. Plastic and Reconstructive Surgery, 100, 1535-1546. https://doi.org/10.1097/00006534-199711000-00026

[4] De la Plaza, R. and Arroyo, J.M. (1988) A New Technique for the Treatment of Palpebral Bags. Plastic and Reconstructive Surgery, 81, 677-687. https://doi.org/10.1097/00006534-198805000-00005

[5] Dacry, S.J., Miller, T.A., Goldberg, R.A., et al. (2008) Magnetic Resonance Imaging Characterization of Orbital Changes with Age and Associated Contributions to Lower Eyelid Prominence. Plastic and Reconstructive Surgery, 122, 921-929. https://doi.org/10.1097/PRS.0b013e3181811ce8

[6] Lee, J.M., Lee, H., Park, M.S., et al. (2011) The Volumetric Change of Orbital Fat with Age in Asians. Annals of Plastic Surgery, 66, 192-195. https://doi.org/10.1097/SAP.0b013e3181e6d052

[7] Innocenti, A., Mori, F., Melita, D., Dreassi, E. and Innocenti, M. (2017) Effects of Orbicularis Oculi Flap Anchorage to the Periosteum of the Upper Orbital Rim on the Lower Eyelid Position after Transcutaneous Blepharoplasty: Statistical Analysis of Clinical Outcomes. Journal of Plastic, Reconstructive \& Aesthetic Surgery, 70, 
385-391. https://doi.org/10.1016/j.bjps.2016.10.019

[8] Adamson, J.E., McCraw, J.B. and Carraway, J.H. (1979) Use of a Muscle Flap in Lower Blepharoplasty. Plastic and Reconstructive Surgery, 63, 359-363.

https://doi.org/10.1097/00006534-197903000-00011

[9] de Castro, C.C. (2004) A Critical Analysis of the Current Surgical Concepts for Lower Blepharoplasty. Plastic and Reconstructive Surgery, 114, 785-793. https://doi.org/10.1097/01.PRS.0000131238.55620.9F

[10] Furnas, D.W. (1981) The Orbicularis Oculi Muscle: Management in Blepharoplasty. Clinics in Plastic Surgery, 8, 687-715. https://doi.org/10.1016/S0094-1298(20)30398-9

[11] Hamra, S.T. (1996) The Role of Orbital Fat Preservation in Facial Aesthetic Surgery: A New Concept. Clinics in Plastic Surgery, 23, 17-28. https://doi.org/10.1016/S0094-1298(20)31138-X

[12] Hamra, S.T. (1992) Repositioning the Orbicularis Oculi Muscle in the Composite Rhytidectomy. Plastic and Reconstructive Surgery, 90, 14-20. https://doi.org/10.1097/00006534-199207000-00002

[13] Hinderer, U.T. (1975) Blepharocanthoplasty with Eyebrow Lift. Plastic and Reconstructive Surgery, 56, 402-409. https://doi.org/10.1097/00006534-197510000-00006

[14] McCord, C.D., Codner, M.A. and Hester, T.R. (1998) Redraping the Inferior Orbicularis Arc. Plastic and Reconstructive Surgery, 102, 2471-2479.

https://doi.org/10.1097/00006534-199812000-00034

[15] Mladick, R.A. (1993) Updated Muscle Suspension and Lower Blepharoplasty. Clinics in Plastic Surgery, 20, 311-315. https://doi.org/10.1016/S0094-1298(20)31223-2

[16] Furnas, D.W. (1978) Festoons of Orbicularis Muscle as a Cause of Baggy Eyelids. Plastic and Reconstructive Surgery, 61, 540-546. https://doi.org/10.1097/00006534-197804000-00007

[17] Zoumalan, C.I., Lattman, J., Zoumalan, R.A., et al. (2010) Orbicularis Suspension Flap and Its Effect on Lower Eyelid Position: A Digital Image Analysis. Archives of Facial Plastic Surgery, 12, 24-29. https://doi.org/10.1001/archfaci.2009.105

[18] Hester, T.R., Ashinoff, R.L. and McCord, C.D. (2006) Managing Postseptal Fat in Periorbital Rejuvenation: Anatomic Intraorbital Replacement Using Passive Septal Tightening. Aesthetic Surgery Journal, 26, 717-724. https://doi.org/10.1016/j.asj.2006.10.002 